
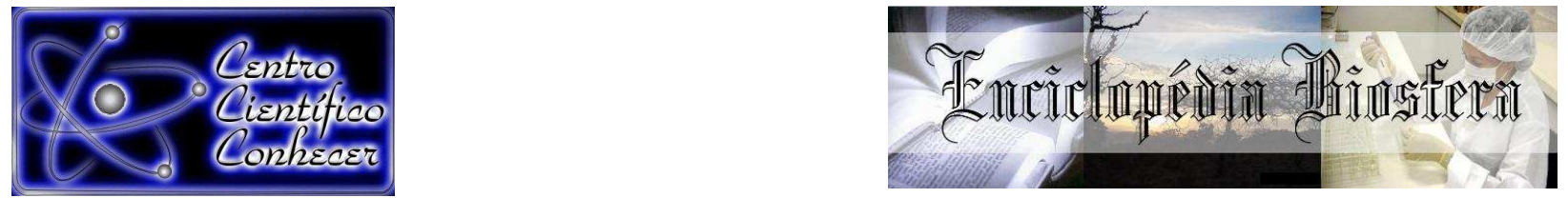

\title{
ANÁLISE PRELIMINAR DE PERIGO DECORRENTE DA OCUPAÇ̃̃O DESORDENADA NO ENTORNO DO PARQUE MUNICIPAL FLAMBOYANT, GOIÂNIA-GOIÁS
}

Layara de Paula Sousa Santos ${ }^{1}$, Sérgio Soares da Silva², Agenor Sousa Santos Neto $^{3}$, Laíse de Paula Sousa Santos ${ }^{4}$, Thiago Augusto Mendes ${ }^{5}$

${ }^{1}$ Mestranda em Engenharia Ambiental e Sanitária pela Universidade Federal de Goiás - UFG, Goiânia, Brasil (layara0912@hotmail.com)

2Mestrando em Engenharia Ambiental e Sanitária pela Universidade Federal de Goiás - UFG, Goiânia, Brasil

${ }^{3}$ Doutorando em Engenharia Elétrica e de Computação pela Universidade Federal de Goiás - UFG, Goiânia, Brasil

${ }^{4}$ Graduanda em Biologia pela Pontifícia Universidade Católica de Goiás - PUC Goiás, Goiânia, Brasil

${ }^{5}$ Instituto Federal de Educação Ciência e Tecnologia de Goiás - IFG, GO, Brasil

Recebido em: 03/10/2016 - Aprovado em: 21/11/2016 - Publicado em: 05/12/2016 DOI: 10.18677/EnciBio_2016B_005

\begin{abstract}
RESUMO
Apesar de o desenvolvimento tecnológico ter proporcionado a consolidação da urbanização, a intensificação e ocupação inadequada de certos ecossistemas advindos do processo de expansão desigual das cidades comprometem a qualidade ambiental da sociedade urbana. Diversos problemas ambientais estão associados ao modo de expansão irregular, dentre estes, destacam-se a ocupação de áreas de preservação permanente, aumento do índice de alagamentos, lançamento de água emergente de lençol freático diretamente em via pública, degradação ambiental, problemas de drenagem pluvial e ocorrência de assoreamentos das nascentes, além de prejuízos à mobilidade urbana e trânsito de veículos. Nesse contexto, a área de estudo foi o Parque Municipal Flamboyant, localizado no Setor Jardim Goiás, em Goiânia/Goiás. Para isso, foi realizado um levantamento para cada um dos perigos decorrentes da ocupação urbana de forma irregular e uso público. Objetivou-se apresentar e discutir o estudo de caso relacionado ao agravamento dos danos ambientais na região do Parque Flamboyant por meio da análise preliminar de perigo, as medidas mitigadoras, também identificou os fatores que favorecem os riscos ambientais. Todos os riscos citados estão sendo vivenciados ou já aconteceram algumas vezes. Um dos problemas mais citados é a impermeabilização urbana decorrente da construção de diversos prédios ao redor do Parque, visto que estas construções em locais de áreas de preservação comprometem a zona de amortecimento do local.
\end{abstract}

PALAVRAS-CHAVE: Danos Ambientais, Expansão Irregular, Impermeabilização Urbana. 


\title{
PRELIMINARY ANALYSIS OF DANGER ARISING OUT OF OCCUPATION Disordered IN SURROUNDING MUNICIPAL PARK FLAMBOYANT, GOIÂNIA- GOIÁS
}

\begin{abstract}
Although technological development have provided the consolidation of urbanization, intensification and inadequate occupation of certain ecosystems arising from unequal expansion process of the cities undertake the environmental quality of urban society. Several environmental problems are associated with irregular expansion mode, among these, is the occupation of permanent preservation areas, increased flooding index, emerging water release water table directly on public roads, environmental degradation, rainwater drainage problems and the occurrence of silting of the springs, as well as damage to urban mobility and vehicle traffic. In this context, the study area was the Municipal Park Flamboyant, located in Sector Jardim Goiás in Goiânia / Goiás. For this, a survey was conducted for each of the dangers of urban occupation erratically and public use. The objective was to present and discuss the case study related to the worsening environmental damage in the Flamboyant Park region through the preliminary hazard analysis, mitigation measures, also identified factors that favor environmental risks. All the risks cited are being experienced or have already happened a few times. One of the most cited problems is urban waterproofing due to the construction of several buildings around the park, as these buildings in conservation areas of local compromise the buffer zone of the site.
\end{abstract}

KEYWORDS: Irregular Expansion, Environmental Damage, Urban Waterproofing.

\section{INTRODUÇÃO}

Diversos problemas ambientais estão associados ao modo de expansão irregular, dentre estes, destacam-se a ocupação de áreas de preservação permanente e aumento do índice de alagamentos e inundações decorrentes da intensificação do escoamento superficial ocasionado pela impermeabilização do solo. Nesse contexto, se insere a região de Goiânia- GO, onde é possível perceber ocupações irregulares, loteamentos mal projetados e ocupação de áreas de risco socioambientais (MORAIS et al., 2012).

No que se refere à qualidade das águas, as bacias mais impactadas são aquelas que sofrem processo de ocupação acelerada. A impermeabilização do solo em áreas urbanas é o maior contribuinte das mudanças hidrológicas na bacia, afetando diretamente os rios urbanos. Isso acontece porque a impermeabilização reduz as taxas de infiltração, as taxas de recarga dos aquíferos e o escoamento básico. Dessa forma, o escoamento superficial é intensificado, aumentando a velocidade, a frequência e a magnitude dos picos de cheia, tais fatores contribuem diretamente para a ocorrência de alagamentos ou inundações (MASCARENHAS et al., 2005).

Segundo RIBEIRO (2010), é necessário investir em infraestrutura nos sistemas de microdrenagem nos grandes centros urbanos a fim de minimizar o fluxo das águas pluviais e consequentemente os impactos ocasionados devido ao excesso de escoamento. Entretanto, percebe-se que a implantação de obras de drenagem e microdrenagem urbanas, nem sempre consideram as características físicas das áreas. Esse fato resulta na maioria das vezes em danos às estruturas 
dos equipamentos implantados, sobretudo em locais propensos à ocorrência de alagamentos (TOLEDO \& CUNHA, 2014).

A falta de visão sistêmica no planejamento da macrodrenagem é o grande responsável pelo estado caótico do controle de alagamentos nas áreas urbanas Brasileiras. E nesse cenário que se destaca a necessidade de planejar ações preventivas e corretivas, onde o problema já se encontra instalado. Para isso, as ações devem ser realizadas de maneira integrada, de forma que abarcam toda a bacia hidrográfica, visto que as infraestruturas básicas não acompanham a retirada da vegetação nativa, ocupação de áreas impróprias, impermeabilização do solo e canalização de rios e córregos (CANHOLI, 2015).

Embora um dos objetivos do Parque Flamboyant seja manter condições mínimas para garantir a preservação das nascentes do Córrego Sumidouro, as grandes obras imobiliárias edificadas em seu entorno têm contribuído para piorar a qualidade ambiental das referidas nascentes. Os danos ambientais causados pela ocupação urbana e as consequências mais perceptíveis determinam a necessidade da adoção de novas alternativas de ocupação, a fim de minimizar as intervenções e proporcionar o equilíbrio entre atividades antrópicas e a natureza.

É nesse cenário que se insere a importância da realização de uma análise preliminar de perigo. Esta análise constitui-se em um processo de ações e decisões a serem realizadas com a finalidade de prevenir futuras complicações. Para isso, foi realizado um levantamento para cada um dos perigos decorrentes à ocupação urbana de forma irregular e mau uso dos ambientes públicos. Diante do exposto, objetivou-se apresentar e discutir o estudo de caso relacionado ao agravamento dos danos ambientais na região do Parque Flamboyant, bem como identificar os fatores que favorecem tais eventos e possíveis medidas mitigadoras.

\section{Importância dos Parques Municipais}

O Sistema Nacional de Unidades de Conservação da Natureza, instituído pela Lei Federal 9.985/2000, define que as principais funções das Unidades de Conservação (UCs) de proteção integral são a proteção total dos recursos naturais e do ecossistema, além do incentivo ao uso indireto, o que compreende a realização de pesquisas científicas, atividades de educação ambiental e turismo ecológico. Já as UCs de uso sustentável têm o objetivo de proporcionar a manutenção dos ecossistemas porque permite a exploração sustentável dos recursos naturais desde que as orientações constantes nos Planos de Manejo destas reservas sejam seguidas (SMUC, 2003).

Ainda de acordo com a referida lei, as unidades de uso sustentável têm a função de compatibilizar a conservação da natureza com o uso sustentável dos recursos naturais. Dessa forma é possível a exploração e o aproveitamento econômico direto de forma regulamentada (SMUC, 2003).

As Unidades de Conservação visam a proteção dos mananciais de abastecimento de água, preservação de ecossistemas e áreas de belezas cênicas. Diversos países têm se esforçado para preservar o ambiente natural e estão preocupados principalmente com grandes ecossistemas, diante da diversidade de espécies animais e vegetais que estão ameaçadas de extinção. No entanto, menor interesse político e científico é destinado a esse tipo de natureza nas áreas urbanas, visto que é possível observar pequena ocorrência destas nas cidades (TYRVAINEN \& VAANANEN, 1998). 


\section{Parque Municipal Flamboyant}

O Parque Flamboyant localiza-se na parte central do Jardim Goiás que após os anos 1970, tornou-se mais urbanizado com a implantação de infraestrutura básica e construção de grandes comércios e serviços (PERES \& BARBOSA, 2010). Até 2006, a área do Parque continha algumas edificações pertencentes ao Antigo Automóvel Clube de Goiás, dentre estas, duas quadras de futebol, uma piscina adulto e uma piscina infantil. Após a implantação do Parque em 2007, a área passou a contar com pistas de caminhada, pistas de bicicleta, caminhos internos, estações de convivência, sede administrativa, núcleo ambiental, estacionamentos, pontes, fonte contemplativa, bica d'água, mobiliários urbanos, parque infantil e iluminação (PRADO, 2014).

Um dos elementos naturais que compõem o Parque é a nascente do Córrego Sumidouro. No local, existe também uma área de brejo que se encontra parcialmente preservada. A vegetação do Parque Flamboyant era composta por buritizais e veredas, atualmente está diversificada e apresenta diversas espécies exóticas. Na Figura 1, observa-se a localização do Parque.

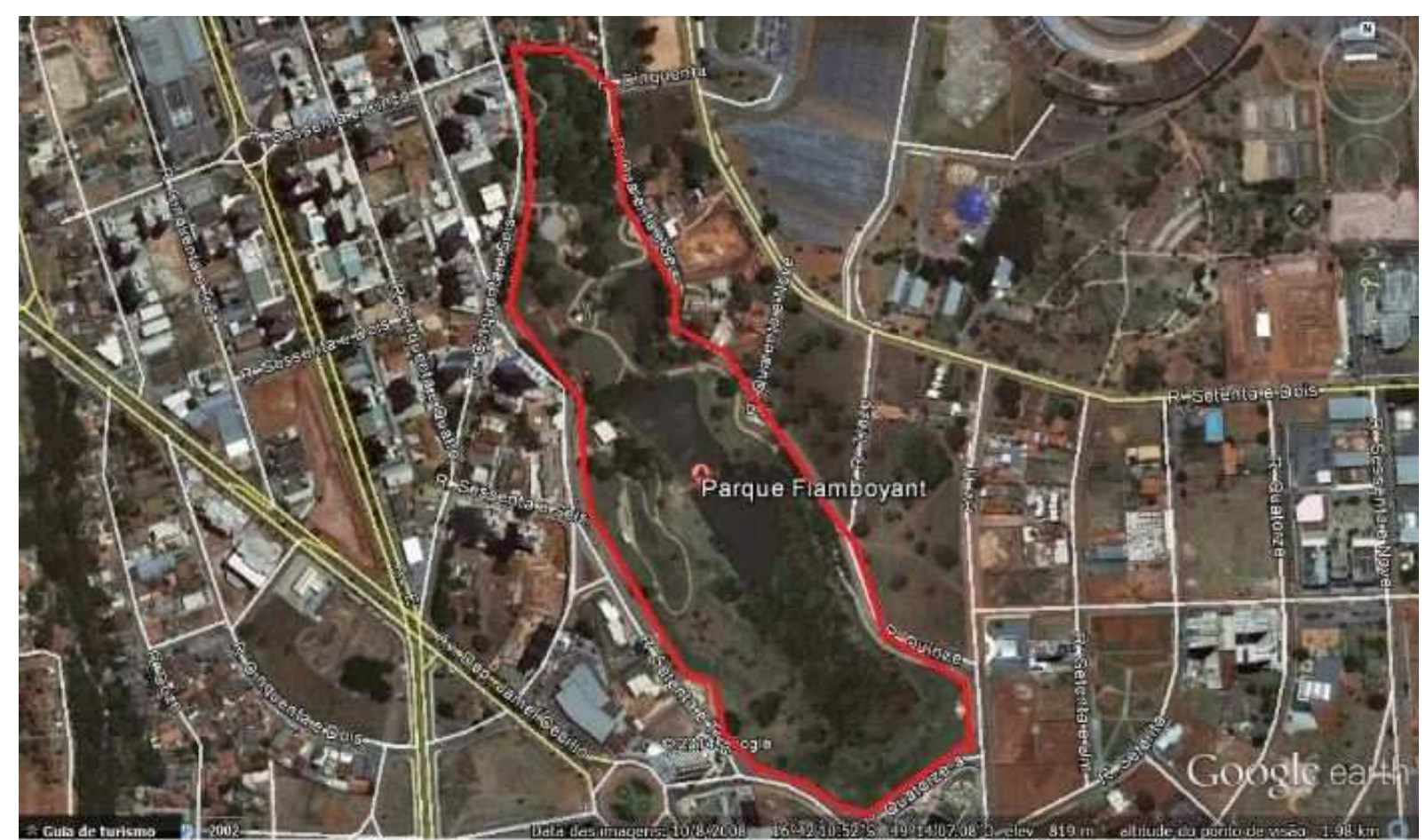

FIGURA 1- Localização do Parque Flamboyant.

Fonte: DA CUNHA FERRÉ et al. (2015).

Estudos realizados por autores como STREGLIO et al. (2013) comprovam que entre os períodos de 1986 a 2010, a vegetação natural do município foi reduzida em torno de $57,2 \%$, sendo que o total remanescente é de apenas 104,1 $\mathrm{Km}^{2}$. As áreas onde houve maior redução da cobertura vegetal apresentam relação com as localidades onde foram criados bairros na década de 1990 e após o ano 2000. De acordo com HAESBART (2007), considerar Goiânia como a "cidade verde" está relacionado com o caráter histórico da construção identitária, sempre representada como "capital ecológica" pela administração municipal, porém tal 
afirmação é antiga e tem sido veiculada pela mídia, ainda que atualmente a realidade se encontre bem distante.

Os Parques urbanos da cidade se destacam como elementos que agregam valor, e se tornam alvo da especulação imobiliária. Associado ao discurso de preservação ambiental, lazer e melhoria da qualidade de vida, houve um crescente aumento do interesse das construtoras pelas terras ao redor do Parque Flamboyant (PRADO, 2014). Ainda que a implementação de novos espaços na cidade seja de fundamental importância para expansão urbana, é necessário que haja planejamento, visto que em função dos interesses econômicos e do crescimento demográfico, torna-se evidente a degradação ambiental (MÁXIMO \& MENESES, 2013).

Diante disso, percebe-se que as cidades contemporâneas apresentam problemas de diversas ordens, estes são determinados pelo crescimento desordenado, pelas mudanças econômicas, sociais, culturais e tecnológicas que se manifestam de maneira mais intensa nas grandes metrópoles (LONDE \& MENDES, 2014).

Os problemas provocados pelo excesso de edifícios no entorno do Parque Flamboyant, no Jardim Goiás, se agravam, também, tendo em vista o perfil dos imóveis da região. Como muitos dos apartamentos são destinados a famílias de classe $A$, os edifícios oferecem duas ou três garagens por imóvel, o que implica em uso excessivo do subsolo, comprometendo o lençol freático com consequências muito perigosas a curto prazo (ROCHA, 2016).

Em um contexto mais amplo, percebe-se que os altos índices de chuvas provocam uma série de problemas nos centros urbanos devido às construções inadequadas, em áreas de preservação. Dentre os agravamentos, destacam-se as enchentes e as enxurradas. Esses danos normalmente seriam evitados se houvesse fiscalização adequada e educação ambiental para informar a comunidade sobre a necessidade da preservação ambiental.

Diante dos diversos impactos negativos encontrados no Parque Municipal Flamboyant e em decorrência do histórico de curso d'água secos e denúncias por parte dos moradores para realização de medidas mitigadoras para amenizar o problema de drenagem local torna-se necessário realizar análise preliminar de perigo. Na Figura 2 a) observa-se a paisagem do Parque, a Figura 2 b) mostra 0 aspecto da nascente do Córrego Sumidouro, onde é possível observar que alguns trechos já apresentam características de mata fechada e outros apresentam vegetação mais esparsa, a Figura 2 c) é referente ao curso d'água com volume reduzido decorrente do elevado número de construções responsáveis pelo rebaixamento do lençol freático aliado ao período de seca.

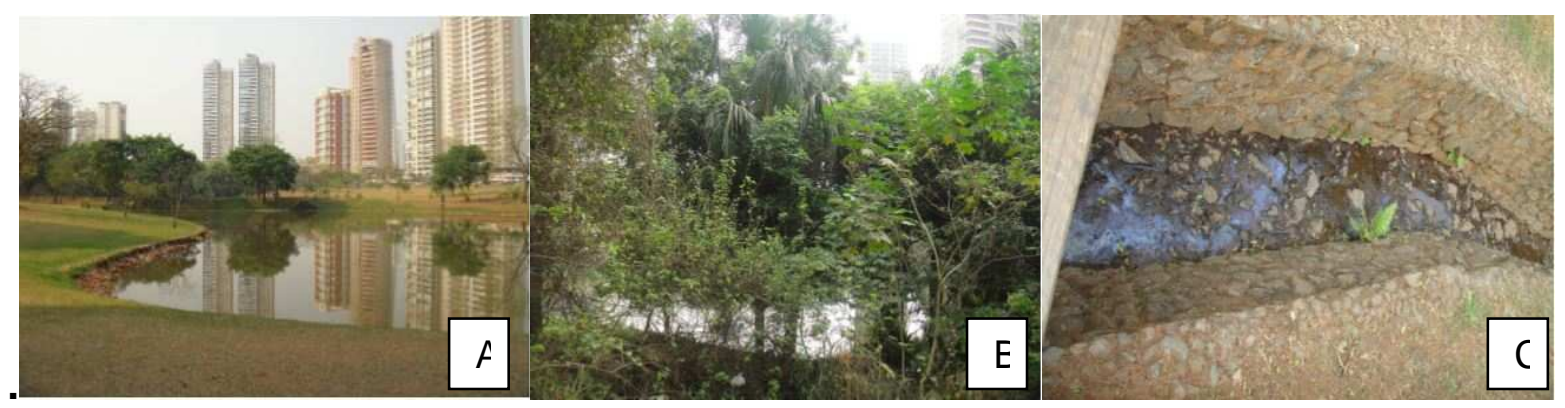

FIGURA 2 - A) Paisagem do Parque Flamboyant; Figura 02 B) Nascente do Córrego Sumidouro; Figura 02 C) Curso d'água com volume reduzido.

Fonte: Conselho de Arquitetura e Urbanismo de Goiás (2012) 


\section{Análise Preliminar de Perigo}

A técnica de Análise Preliminar de Perigos possui um formato padrão tabular, onde para cada perigo identificado são levantadas as possíveis causas, efeitos potenciais, medidas de controle básicas para cada caso, a nível preventivo ou corretivo. Os perigos identificados por esse método são avaliados com relação à frequência de ocorrência, grau de severidade e nível de suas consequências considerando os potenciais danos resultantes às pessoas, materiais e comunidade. Os resultados dessa Análise são apresentados em planilhas de análise.

A utilização da Análise Preliminar de Perigo tem como objetivo minimizar o potencial de ocorrência de acidentes, utilizando técnicas de prevenção e/ou de proteção. A identificação de perigos tem como objetivo encontrar os possíveis eventos indesejáveis que podem proporcionar a concretização do perigo, por meio da adoção de hipóteses acidentais que poderão acarretar consequências significativas (PIOVESAN \& COUTO, 2010).

\section{MATERIAL E MÉTODOS}

Para realização desta pesquisa foram utilizadas informações obtidas em livros e artigos científicos adquiridos no Portal de Periódicos Capes e Portal Scielo, e também do Plano de Manejo do Parque Flamboyant. As informações foram analisadas a fim de identificar riscos ambientais envolvendo características como: cobertura vegetal, solo, situação das áreas de preservação permanente, fauna e também aspectos antrópicos como: expansão urbana, construções inadequadas, drenagem e impermeabilização.

Neste método foram estabelecidos níveis hierárquicos de risco de acordo com a proposição de AGUIAR (2009) para descrever as intensidades e suscetibilidade ao risco de danos ambientais. O nível de risco mais alto é o 5, identificado como crítico; o nível 4 vem em segundo lugar, sendo considerado sério; logo após vem o nível 3 que indica um índice de risco moderado; no nível 2, o indicador é menor; e por último o menor grau de intensidade de risco é o nível 1, considerado desprezível, de acordo com a matriz de risco e severidade representada pela Figura 3.

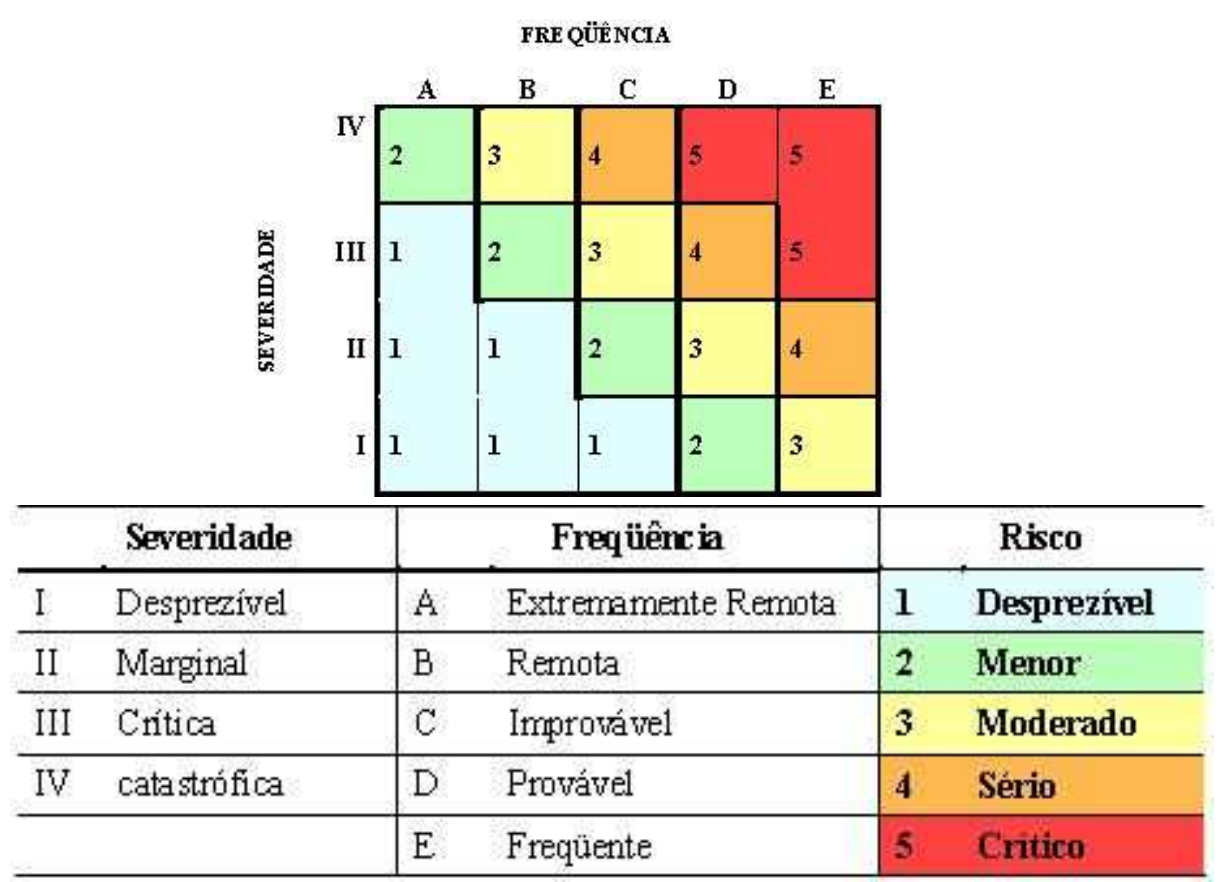

FIGURA 3 - Matriz de risco. Fonte: AGUIAR (2009) 
Para simplificar a análise preliminar de perigo, é apresentada no quadro 1 que mostra as categorias de frequência para realização de uma Análise Preliminar de Risco.

QUADRO 1 - Categorias de frequências de ocorrências dos cenários

\begin{tabular}{|c|c|c|c|}
\hline Categoria & Denominação & Faixa de Frequência (anual) & Descrição \\
\hline$A$ & extremamente remota & $\mathrm{f}<10^{-} \square$ & $\begin{array}{l}\text { Conceitualmente } \\
\text { possível, mas } \\
\text { extremamente } \\
\text { improvável de } \\
\text { acontecer. }\end{array}$ \\
\hline B & remota & $10^{-} \square<\mathrm{f}<10^{-3}$ & $\begin{array}{l}\text { Não esperado } \\
\text { ocorrer durante a } \\
\text { vida útil do } \\
\text { processo. }\end{array}$ \\
\hline $\mathrm{C}$ & improvável & $10^{-3}<f<10^{-2}$ & $\begin{array}{l}\text { Pouco provável de } \\
\text { ocorrer durante a } \\
\text { vida útil do } \\
\text { processo. }\end{array}$ \\
\hline D & provável & $10^{-2}<f<10^{-1}$ & $\begin{array}{l}\text { Esperado ocorrer } \\
\text { até uma vez } \\
\text { durante a vida útil } \\
\text { do processo. }\end{array}$ \\
\hline$E$ & frequente & $f>10^{-1}$ & $\begin{array}{l}\text { Esperado ocorrer } \\
\text { várias vezes } \\
\text { durante a vida útil } \\
\text { do processo. }\end{array}$ \\
\hline
\end{tabular}

Fonte: AGUIAR (2009)

O quadro 2 mostra as categorias de severidade, as quais fornecem uma indicação qualitativa da severidade esperada.

QUADRO 2 - Categorias de severidade dos perigos identificados

\section{Categoria Denominação Descrição/Característica}

\begin{tabular}{ccc}
\hline I & baixa & $\begin{array}{r}\text { Os danos ambientais não resultarão em uma } \\
\text { degradação maior do sistema. }\end{array}$ \\
\hline II & moderada & $\begin{array}{r}\text { Os danos irão degradar o sistema em uma certa } \\
\text { extensão, porém sem comprometê-lo seriamente. }\end{array}$ \\
\hline III & crítica & Os danos provocados resultam riscos inaceitáveis. \\
\hline IV & catastrófica & $\begin{array}{l}\text { Severa degradação ao sistema e ao meio ambiente, } \\
\text { resultando em comprometimento total da qualidade } \\
\text { ambiental. }\end{array}$ \\
\hline
\end{tabular}

Fonte: Adaptado de AGUIAR (2009) 
O preenchimento da planilha de Análise Preliminar de Perigo corresponde ao levantamento do número de cenários de acidentes identificados por categorias de frequência e de severidade, identificando os cenários críticos ou catastróficos. Nesse contexto, a aplicabilidade da gestão de riscos em Parques Municipais, tem a função de auxiliar na tomada de decisões, visto que a análise de risco proporciona que algumas ações sejam priorizadas com a finalidade de reparar determinados problemas.

\section{RESULTADOS E DISCUSSÃO}

De acordo com o método proposto por AGUIAR (2009), foi possível construir - quadro 2 que demonstra a análise preliminar de perigo, a qual prevê a possibilidade de ocorrência destes, bem como as recomendações para evitá-los. Por meio da análise da Tabela 3, percebe-se que a maioria dos riscos é decorrente da expansão urbana e falta de consciência ambiental por parte dos visitantes.

Todos os riscos citados estão sendo vivenciados ou já aconteceram algumas vezes. Um dos problemas mais citados é a impermeabilização urbana decorrente da construção de diversos prédios ao redor do Parque, visto que estas construções em locais de áreas de preservação comprometem a zona de amortecimento do local, o que acaba impactando negativamente diversos aspectos da natureza, incluindo o comprometimento das nascentes, fauna e flora e favorecimento da ocorrência de danos à população que se concentra mais à jusante na bacia, os quais podem ocorrer por meio de enchentes e/ou inundações.

As recomendações descritas no quadro 3 deveriam ser adotadas frequentemente com a finalidade de evitar maiores danos. Há de se ressaltar que os danos provocados por alguns riscos são irreversíveis, e ainda que haja medidas mitigadoras torna-se evidente os agravos de doenças intensificadas pela poluição, comprometimento ambiental e diminuição da qualidade de vida.

O município de Goiânia precisa destinar mais recursos e empenho para efetivação dos subprogramas de manejo da fauna e flora e para o subprograma de pesquisas e monitoramento. Uma das alternativas seria intensificar o contato com Universidades para efetuar estudos e pesquisas e também realizar programas de educação ambiental por meio de parcerias com Organizações Não Governamentais.

A proteção do Parque consiste em outro aspecto que carece de melhorias, para isso é importante realizar treinamento para os funcionários de vigilância e administração, desenvolver um sistema eficaz de fiscalização e sinalizar adequadamente o local com placas de zoneamento. 
QUADRO 3 - Análise Preliminar de Perigo do Parque Flamboyant

\begin{tabular}{|c|c|c|c|c|c|c|}
\hline Perigo & Causas & Consequências & Frequência & Severidade & Risco & Recomendações \\
\hline $\begin{array}{l}\text { Descaracterização } \\
\text { do solo }\end{array}$ & $\begin{array}{l}\text { Antropização com elevada } \\
\text { intensidade e ação enxurradas. }\end{array}$ & $\begin{array}{l}\text { Comprometimento das nascentes } \\
\text { do Parque provocando o } \\
\text { assoreamento e a introdução de } \\
\text { resíduos dentro dos lagos. }\end{array}$ & Frequente & Orítica & Sério & $\begin{array}{l}\text { Restauração da vegetação original, retirada frequente } \\
\text { de resíduos. }\end{array}$ \\
\hline $\begin{array}{l}\text { Diminuição do } \\
\text { volume de águas } \\
\text { doscorpos hídricos }\end{array}$ & $\begin{array}{l}\text { Pebaixamento do lençol freático } \\
\text { em decorrência das construçées } \\
\text { dos subsolos dos prédios; Áreas } \\
\text { de Preservação Permanente } \\
\text { Parcialmente Preservadas. }\end{array}$ & $\begin{array}{l}\text { Redução da umidade do solo e } \\
\text { redução significativa das águas dos } \\
\text { corpos hídricos locais. }\end{array}$ & Frequente & Catastrófica & Orítico & $\begin{array}{c}\text { Pecomposição da Áreas de Preservação Permanente, } \\
\text { garantia de maior índice de áreas permeáveis, } \\
\text { implantação de leis que restrinjam a quantidade e } \\
\text { altura das edificaçães nas proximidades do Parque, } \\
\text { adoção de medidas mitigadoras como adequação de } \\
\text { caixas de drenagem na parte mais alta do Parque, para } \\
\text { percolação das águas de chuva. }\end{array}$ \\
\hline $\begin{array}{l}\text { Vegetação } \\
\text { antropizada }\end{array}$ & $\begin{array}{l}\text { Desmatameto, plantio de } \\
\text { espécies exóticas. }\end{array}$ & $\begin{array}{l}\text { Comprometimento das nascentes, } \\
\text { assoreamento, al teração da fauna } \\
\text { silvestre, aumento da } \\
\text { luminosidade interna do Parque } \\
\text { em decorrência dos } \\
\text { desmatamentos e proliferação de } \\
\text { cipós em grande quantidade. }\end{array}$ & Provável & Orítico & Sério & $\begin{array}{l}\text { Desativação de algumas trilhas internas que se } \\
\text { encontram no interior da mata, œm o plantio de } \\
\text { espécies nativas adaptadas à ambientes sombreados, } \\
\text { recuperação das nascentese também da vegetação œom } \\
\text { espécies nativas adequadas, recomposição florística, } \\
\text { œmbate aos formigueirose cupinzeiros. }\end{array}$ \\
\hline $\begin{array}{l}\text { Desaparecimento } \\
\text { de nascentes }\end{array}$ & $\begin{array}{l}\text { Inúmeras construções no entorno } \\
\text { do Parque. }\end{array}$ & $\begin{array}{l}\text { Interferência no lençol freático e } \\
\text { consequente redução de } \\
\text { alimentação dos lagos, causando } \\
\text { problemas intensosà fauna e à } \\
\text { flora. }\end{array}$ & Frequente & Catastrófica & Orítico & $\begin{array}{l}\text { Coibir a escavação dos solos em períodos críticos, } \\
\text { separação das águas servidas das águas de drenagem, } \\
\text { aumento da permeabilidade do solo e aumento da } \\
\text { vegetação à margem das nascentes. }\end{array}$ \\
\hline Eutrofização & $\begin{array}{l}\text { Pedução da vazão daágua no } \\
\text { período seco, as enxurradas } \\
\text { trazem muita matéria ogânica para } \\
\text { dentro dos lagos, a introdução de } \\
\text { aves nos lagos aumentam a } \\
\text { matéria orgânica, a alimentação } \\
\text { inadequada aos animais dos lagos } \\
\text { pelos visitantes. }\end{array}$ & $\begin{array}{l}\text { Morte de peixese } \\
\text { comprometimento da qualidade da } \\
\text { água. }\end{array}$ & Frequente & Orítico & Sério & $\begin{array}{c}\text { Mudança de hábitos da população do entorno, quanto } \\
\text { dosfuturos visitantes do Parque. Manejo adequado dos } \\
\text { animais. }\end{array}$ \\
\hline
\end{tabular}




\begin{tabular}{|c|c|c|c|c|c|c|}
\hline Perigo & Causas & Consequências & Frequência & Severidade & Fisco & Pecomendações \\
\hline Excesso de lixo & $\begin{array}{l}\text { Lixeiras insuficientes, coletade } \\
\text { lixo irregular, falta de } \\
\text { conscientização dos usuários. }\end{array}$ & $\begin{array}{l}\text { Alteração da qualidade do solo e } \\
\text { das águas, propagação de doenças. }\end{array}$ & Provável & Orítico & Sério & $\begin{array}{l}\text { Aumentar a quantidade de coletores, regularizar a } \\
\text { coleta, estabelecimento de programas de manutenção, } \\
\text { limpeza e educação ambiental. }\end{array}$ \\
\hline $\begin{array}{l}\text { Ausência de } \\
\text { controle de } \\
\text { visitação }\end{array}$ & $\begin{array}{l}\text { Erosão, compactação do solo, } \\
\text { pixações em monumentos. }\end{array}$ & $\begin{array}{l}\text { Diminuição da absorção de água, } \\
\text { morte da microfauna, danos ao } \\
\text { patrimômio público. }\end{array}$ & Provável & Orítico & Sério & Melhorar a segurança do local. \\
\hline $\begin{array}{l}\text { Excesso de } \\
\text { construções }\end{array}$ & Degradação do meio natural. & $\begin{array}{l}\text { Risco de desaparecimento de } \\
\text { nascentes, aumento da densidade } \\
\text { populacional, trânsito caótico. }\end{array}$ & Frequente & Catastrófica & Orítico & $\begin{array}{c}\text { Planejamento de construçães adequadas, redução do } \\
\text { número de subsolos e altura das edificações, adoção de } \\
\text { medidas mitigadoras como construção de caixas de } \\
\text { drenagem. }\end{array}$ \\
\hline Incêndio & $\begin{array}{l}\text { Disposição inadequada de pontas } \\
\text { de cigarro acesas. }\end{array}$ & Morte da fauna e daflora. & Provável & Catastrófica & Orítico & Fiscalização. \\
\hline $\begin{array}{l}\text { Exploração dos } \\
\text { recursos vivos }\end{array}$ & $\begin{array}{l}\text { Alteração da reprodução de } \\
\text { espécies. }\end{array}$ & Morte da fauna e da flora. & Provável & Orítico & Sério & Fiscalização e sinal ização. \\
\hline Falta de segurança & $\begin{array}{l}\text { Pouca vigilância, falta de } \\
\text { fiscalização e segurança. }\end{array}$ & $\begin{array}{l}\text { Insegurança por parte da população } \\
\text { e vendedores ambulantes. }\end{array}$ & Frequente & Orítico & Sério & Monitoramento contínuo e atuação da fiscalização. \\
\hline $\begin{array}{l}\text { Impermeabilização } \\
\text { do solo }\end{array}$ & Excesso de construções. & $\begin{array}{l}\text { Aumento da possibilidade de } \\
\text { alagamentos e transbordamentos. }\end{array}$ & Frequente & Orítico & Sério & $\begin{array}{l}\text { Aumentar o índice de áreas permeáveis, adotar } \\
\text { medidas de drenagem sustentável. }\end{array}$ \\
\hline
\end{tabular}




\section{CONCLUSÃO}

Analisando o estudo de caso do Parque Flamboyant sob a ótica ambiental e de acordo com as recomendações abordadas para prevenção de perigo, percebe-se que efetivamente a pressão imobiliária no entorno do local é um problema que tem contado com o descaso das autoridades competentes.

A origem da maioria dos problemas citados está relacionada com a especulação imobiliária e o adensamento populacional. Ainda que os impactos negativos mais evidentes tenham sido representados, sabe-se que existem também impactos indiretos que afetam a qualidade de vida da população, destacando-se problemas como perda do ambiente natural para o lazer, impactos visuais, alteração do microclima e depreciação da qualidade química da água.

Verifica-se que não há planejamento ambiental das construções, visto que afetam até mesmo a zona de amortecimento da Unidade de Conservação em questão, além do uso excessivo de subsolo causado pelos empreendimentos implantados. Nesse sentido, o Poder Público tem competências para editar leis relativas ao Planejamento do local, portanto, poderia colocar em vigor regulamentações sobre o meio ambiente e limitações ao direito de construir.

Como forma de evidenciar os perigos e indicar medidas mitigadoras, a análise preliminar de perigo constitui-se em um método utilizado para minimizar os riscos ambientais, utilizando técnicas de prevenção ou de proteção. Dessa forma, proporciona benefícios e conscientização para a problemática ambiental urbana.

Para melhorar os resultados de pesquisas futuras, sugere-se que todos os subprogramas constantes no Plano de Manejo do Parque Flamboyant, que ainda não foram finalizados sejam concluídos, a exemplo dos seguintes subprogramas: manejo da flora, manejo da fauna, análises da água, pesquisa e monitoramento, educação ambiental, turismo, relações públicas, administração, manutenção, cooperação interinstitucional e recreação. As conclusões dessas atividades proporcionarão resultados mais precisos para estudos de Análise Preliminar de Perigo.

\section{REFERÊNCIAS}

AGUIAR, L. A. Metodologias de Análise de Riscos: App e Hazop. 2009. 29p. Disponível em: http://professor.pucgoias.edu.br/SiteDocente/admin/arquivosUpload/13179/material/ APP_e_HAZOP.pdf>. Acesso em: 20 de junho 2016.

AMMA - Agência Municipal do Meio Ambiente. Disponível em: <http://www.goiania.go.gov.br/shtml/amma/apresentacao.shtml> Acesso em: 5 de junho de 2016.

CANHOLI, A. Drenagem urbana e controle de enchentes. Oficina de Textos, 2015, $384 \mathrm{p}$.

CONSELHO DE ARQUITETURA E URBANISMO DE GOIÁS. Relatório 4 Parque Flamboyant, 2012. Disponível em: < http://www.caugo.org.br/wpcontent/uploads/2013/06/4-Parque-Flamboyant.pdf> Acesso em: 02 de junho de 2016. 
DA CUNHA FERRÉ, T.; GONÇALVES, R. A; SILVA NETO, C. M; CALIL, F. M. Riqueza Florística do Parque Municipal Flamboyant Lourival Louza no Município de Goiânia - GO. Enciclopédia Biosfera, v. 11, n.22, p. 2431-2542. 2015. Disponível em: < http://dx.doi.org/10.18677/Enciclopedia_Biosfera_2015_223>. doi: 10.18677/Enciclopedia_Biosfera_2015_223.

HAESBAERT, R. Identidades territoriais: entre a multiterritorialidade e a reclusão territorial (ou: do hibridismo cultural à essencialização das identidades). Identidades e territórios: questões e olhares contemporâneos. Rio de Janeiro, v.3, n.1, p. 33$56,2007$.

LONDE, P.R.; MENDES, P. C. A influência das áreas verdes na qualidade de vida urbana. Hygeia: Revista Brasileira de Geografia Médica e da Saúde, v. 10, n. 18, p. 264, 2014. Disponível em: <

http://www.seer.ufu.br/index.php/hygeia/article/viewFile/26487/14869>.

MASCARENHAS, F. C. B.; MIGUEZ, M. G.; MAGALHÃES, L. P. C.; PRODANOFF, J. H. A. On-site stormwater detention as an alternative flood control measure in ultraurban environments in developing countries. In: International Symposium on Sustainable Water Management for Large Cities, held during the Seventh Scientific Assembly of the International Association of Hydrological Sciences, Foz do Iguaçu, Brazil, 3-9 April 2005. IAHS Press, 2005. p. 196-202.

MÁXIMO, P. H; MENESES, M. R. Escalas e dinâmicas da cidade contemporânea brasileira: os parques urbanos de Goiânia e suas dicotomias. Anais: Encontros Nacionais da ANPUR, v. 15, 2013.

MORAIS, L. B; RIBEIRO, A. R; HORA, K. E. R. Avaliação dos riscos ambientais da ocupação urbana da sub bacia do córrego Vaca Brava, Goiania-Goiás. III Congresso Brasileiro de Gestão Ambiental, 2012.

PERES, M. L. C; BARBOSA, Y. M. O imaginário na reprodução da natureza no espaço urbano: Parques Vaca Brava e Flamboyant. Contemporânea, v. 8, n. 1, p. 196-204, 2010. Disponível em: $<$ http://www.epublicacoes.uerj.br/index.php/contemporanea/article/view/706/696>.

PIOVESAN, G. Z; COUTO, M. Análise preliminar de perigo para o uso público no parque estadual do lajeado-TO. Revista Acadêmica Observatório de Inovação do Turismo, v. 5, n. 1, p. 05-05, 2010. Disponível em: < http://publicacoes.unigranrio.com.br/index.php/raoit/article/view/3512>. Doi: 10.12660 .

PRADO, D. A. R. Apropriação e usos para lazer no Parque Flamboyant. Geografia (Londrina), v. 22, n. 3, p. 5-25, 2014.

ROCHA, R.M; BARREIRA, A. A. Empreendimentos Imobiliários. Áreas feitas por construtoras correm risco por causa do excesso de construções nos arredores. Disponível em http://www.penseambientalmente.com/disciplinas/cienciasamb/ia/texto2.pdf>. Acesso em: 11 de maio de 2016. 
STREGLIO, C. F. C; FERREIRA, D. T; DE OLIVEIRA, I. J. O Processo de Expansão Urbana e seus Reflexos na Redução da Cobertura Vegetal no Município de GoiâniaGO. Raega-O Espaço Geográfico em Análise, v. 28, n.2, p. 181-197, 2013. Disponível em: <http://revistas.ufpr.br/raega/article/viewFile/32306/20522>. doi: 10.5380

SMUC/GNA. Sistema Municipal de Unidades de Conservação e Parques Urbanos de Goiânia. Minuta do Projeto de Lei que Institui o Sistema Municipal de Unidades de Conservação e Parques Urbanos de Goiânia, outubro de 2003.

TOLEDO, M. D.; CUNHA, C. M. P. A importância do conhecimento pedológico/ geomorfológico e geotécnico para a concepção de estruturas de microdrenagem urbana em áreas de fragilidade. Observatório Geográfico da América Latina, 2014. Disponível em: http://www.observatoriogeograficoamericalatina.org.mx/egal14/Procesosambientales /Geomorfologia/01.pdf>.

TYRVÄINEN, L.; VÄÄNÄNEN, H.; The economic value of urban forest amenities: an application of the contingent valuation method. Landscape and Urban Planning, v. 43, n. 1, p. 105-118, 1998. Disponível em:< http://www.sciencedirect.com/science/article/pii/S0169204698001030>. Doi: 10.1016/0169-2046(98)00103-0. 